\title{
Report on the 20th international shock interaction symposium
}

\author{
N. Apazidis
}

Received: 1 October 2012 / Accepted: 3 October 2012 / Published online: 11 October 2012

(C) Springer-Verlag Berlin Heidelberg 2012

The 20th international shock interaction symposium (ISIS20) was held at KTH (Royal Institute of Technology), Stockholm, Sweden, between 20 and 24 August, 2012. It is a nice and by now established tradition to hold smaller shock symposia between the biannual international symposia on shock waves. Previously known as the Mach Reflection Symposia, they are now organized in the present form.

The symposium was for the first time hosted by KTH in Stockholm, Sweden and on behalf of my home University, I would like to express my gratitude to the International Advisory Committee and especially to Professor K. Takayama, Japan and Professor G. Ben-Dor, Israel for proposing the KTH to organize this meeting as well as for their support in the course of preparations.

Although smaller in size, ISIS20 provided a wide scope of high-quality contributions to the current shock wave research including shock propagation and reflection, nozzle and jet flows, shock focusing, multiphase flows, shockboundary layer interaction, shock diffraction, hypersonic flows, impact, detonation and combustion, shock wave structure, and stability. Altogether, there were 57 contributions from 13 countries representing Asia, Europe, and North America. The nations from which the participants, including the accompanying persons, originated were as follows:
China (1), France (3), Germany (4), India (3), Israel (21), Japan (11), The Netherlands (2), Norway (3), Poland (3), Russia (15), Sweden (11), UK (5), and USA (7).

One of the major issues for each scientific field, including our own, is the issue of regrowth and inflow of new blood. In this respect, ISIS20 turned out to be very promising by exposing a large number of high-quality presentations by young researchers.

The social program included a reception at the City Hall of Stockholm on Wednesday, August 22, 2012. The participants were welcomed by the vice-mayor of Stockholm, Mr. Fridebäck. In a return speech, Professor Takayama thanked the City of Stockholm on behalf of the conference participants for the invitation. The reception was accompanied by a guided tour of the City Hall.

I would like to acknowledge the financial support provided to this meeting by The Swedish Research Foundation (VR), KTH, Linné Flow Centre and the GöranGustafssons Foundation. I would also like to thank the City of Stockholm for hosting the reception at the City Hall on Wednesday, August 22, 2012. Finally, I would like thank all participants for their contribution to the successful implementation of the ISIS20.
N. Apazidis is the Chairman of ISIS20.

N. Apazidis $(\varangle)$

Department of Mechanics, KTH, 10044 Stockholm, Sweden

e-mail: nap@mech.kth.se 